\title{
The Literature Review on Compensation System Design
}

\author{
Peidan Hong \\ School of Management, Jinan University, Guangzhou, China \\ Email:pdhong12@163.com
}

How to cite this paper: Hong, P.D. (2017) The Literature Review on Compensation System Design. Modern Economy, 8, 1119-1128.

https://doi.org/10.4236/me.2017.89077

Received: August 29, 2017

Accepted: September 19, 2017

Published: September 22, 2017

Copyright $\odot 2017$ by author and Scientific Research Publishing Inc. This work is licensed under the Creative Commons Attribution International License (CC BY 4.0).

http://creativecommons.org/licenses/by/4.0/

\begin{abstract}
In the fierce market competition environment, the development of enterprises is inseparable from the effective operation of management control system. As an essential part of management control system, the importance of compensation system design is beyond doubt. This paper summarizes the latest research on the considerations of compensation system design, and the influences of compensation system design on performance and financial misreporting, in the hope of being a suggestion on following research.
\end{abstract}

\section{Keywords}

Compensation System Design, Performance, Financial Misreporting

\section{Introduction}

With the rapid development of economy, the market competition is increasingly fierce and enterprises are faced with more severe policy and economic environment. In order to survive and develop, enterprises need to strengthen internal management effectively and attach great importance to the outside-in feedback management, that is to say, enterprises should establish an effective management control system. As an essential part of management control system, compensation system design is undoubtedly of great importance. Compensation system is one of the important tools for enterprises to carry out enterprise management and pursue business success. In the fierce market competition environment, the corporation's core competencies are vital to the survival and development of the enterprises. Scientific and appropriate compensation system can help enterprises to build core competencies and achieve common development of enterprises and employees. Consequently, it has become an important proposition to design scientific and appropriate compensation system by applying advanced management philosophy. 
Research on compensation system design shows us its role in the enterprises and enriches people's understanding of compensation system design, which is beneficial for people to apply it well. This paper summarizes the latest research on compensation system design, aiming to contribute to research and practice in this field. The rest of the paper is organized as follows: Section 2 sets forth the considerations of compensation system design, including the applicability of Relative performance evaluation (RPE), the considerations of directors' compensation and the match between compensation system design and the organization. Section 3 presents the influences of compensation system design on performance and financial misreporting. Section 4 provides concluding remarks.

\section{The Considerations of Compensation System Design}

\subsection{The Applicability of Relative Performance Evaluation}

Relative performance evaluation (RPE) is the process of comparing performance among workers, which is to reward employees' performance based on the performance of the relative reference group. Taking the listed companies in China from 2001 to 2008 as a sample, Hu, Y.Q. and Zhou, H. [1] find evidences to support the use of RPE, when dividing companies in the same industry into the reference group and measuring the company's performance by return on assets. Furthermore, the paper shows that the use of RPE in executive compensation contracts varies negatively with a firm's level of growth options. Albuquerque, A.M. [2] also conducts a test whether growth-option firms should use CEO compensation contracts based on RPE. In general, for the reason that growthoption firms are in more volatile environments, the use of RPE can avoid exogenous shocks on CEOs and reduce the risk faced by them. However, for high-growth-option firms, it's difficult to find peer groups which captures common risk exposure, thus the implementation effect of the use of RPE has been affected. The paper finds that high-growth-option firms rarely use RPE to evaluate the performance of CEO.

\subsection{The Considerations of Directors' Compensation}

First of all, many scholars have done a lot of research on the compensation of employees and managers in the compensation system design, but few scholars have carried out in-depth research on the compensation of directors. In recent years, some scholars at home and abroad have creatively studied the considerations of directors' compensation.

Equity-based compensation will link directors' compensation to the long-term value of the firm, which is regarded as an effective way to design directors' compensation. However, Drymiotes, G. and Sivaramakrishnan, K. [3] state that longterm incentives alone may not prompt directors to perform their role in supervising corporate executives effectively. Enterprises should also implement some short-term incentives for directors, especially using the same short-term measure used to evaluate managers. The combination of short-term and long-term 
incentives is more beneficial to enhance the effectiveness of the board on monitoring corporate executives. Zhu, T. [4] conducts a research about the influence of director's compensation on CEO's compensation, and finds that though both director's supervision compensation and excess compensation and are positively related to CEO's compensation, but the effects on firm's future performance are dramatically different. The higher director's supervision compensation is, the better the future performance is. However, the higher director's excess compensation causes worse future performance. That is to say, the relationship between director and CEO is complicated, which could be supervision or collusion. Moreover, the effect of collusion is stronger than that of supervision. The results show that it's essential to further clarify the differences in the functions of directors and CEOs, and pay attention to design the compensation that matches the supervisory functions of the directors, which is an important way to improve the performance of the company.

\subsection{The Match between Compensation System Design and the Organization}

Many previous researches on compensation system design focused on the specific compensation design of employees and executives, and rarely involved in compensation system design at the organizational level. In recent years, many scholars have gradually paid attention to compensation system design from the angle of the organizational level.

Díaz-Fernández, M., López-Cabrales, A. and Valle-Cabrera, R. [5] suggest that the compensation system design should be matched with the corporate strategy. Taking manufacturing enterprises as a sample, the article finds that it's because the compensation system design motivates employees to cultivate competencies matched with the corporate strategy that the compensation system design makes an enormous effect. In general, the implementation of corporate strategy requires employees to have corresponding competencies, thus the design of compensation system should be guided by these competencies. The compensation system design should be matched with the corporate strategy.

Bushardt, S.C., Glascoff, D.W. and Doty, D.H. [6] propose the design of compensation system should be consistent with organizational culture. Madhani, P.M. [7] shows that if the compensation system design is not congruent with organizational culture, it will easily lead to some adverse consequences. On the other hand, organizational culture which is matched with compensation system design will become a competitive advantage for the enterprise.

Some scholars in China have also studied the compensation system design at the organizational level. Xia, N. and Dong, Y. [8] propose that when designing the compensation system, enterprises should not only consider the absolute value and relative value of compensation, but also pay attention to the influence of specific circumstances of the enterprises on pay gap, such as the executive team's collaboration needs, financial risk, technical complexity and firm size, etc. 


\section{The Influences of Compensation System Design}

\subsection{Compensation System Design and Performance}

Many scholars have studied the relationship between compensation system design and the performance of enterprises, and found that compensation has an incentive effect on performance. In recent years, many scholars have carried out in-depth research on the relationship between compensation system design and performance, mainly involved in the following three aspects: the in-depth research about CEO's compensation; comprehensive consideration of the compensation of individual and team, employee and executive; the influence factors of pay-performance sensitivity.

\subsubsection{The In-Depth Research about CEO's Compensation}

Many scholars have conducted research about the relationship between CEO's compensation and the performance of enterprises. And Banker, R.D., et al. [9] divides CEO's compensation into salary and bonus, which enriches related research. The reason for dividing CEO's compensation is that salary is adjusted to meet the reservation utility and information rent, and is positively correlated over time to reflect ability, while bonus serves to address moral hazard and adverse selection by separating high-ability agents into riskier contracts. The paper finds that salary is positively related to past performance and bonus is negatively related to past performance, no matter whether the CEO is newly hired or not. Additionally, salary is positively related to future performance while bonus is not. Consequently, decomposing compensation into salary and bonus is beneficial to comprehend the interaction between incentives and performance.

\subsubsection{Comprehensive Consideration of the Compensation of Individual and Team, Employee and Executive}

Many previous studies separately considered individual and team compensation, without combining them. The same situation existed in the compensation of employee and executive. In recent years, many scholars at home and abroad have made a contribution to the research in this aspect.

Chen, C.X., Williamson, M.G. and Zhou, F.H. [10] studied the impacts of individual-based and group-based compensation on performance. The results show that, in the design of the compensation system, compared with individual effort, enterprises are supposed to attach importance to the degree of team effort, so as to promote the innovation of the team and improve the performance of enterprises.

In the aspect of the relationship between employees and executives, Chen, D.H., Fan, C.L. and Shen, Y.J. [11] find that the compensation of employees and executives are both positively associated with the performance of enterprises, which indicates the two kinds of compensation incentive have a positive effect on the growth of performance. The pay-performance sensitivity of executives is significantly higher than that of employees. Moreover, the stronger the synchronization between the compensation of executive and that of employees is, the 
bigger the encouraging effect on future performance is. Taking state-owned listed firms in manufacturing industry from 2003 to 2010 as a sample, Li, W.J. and $\mathrm{Hu}$, Y.M. [12] examine the different incentive effect of pay gap on executives and employees. They find that pay gap between executives and employees in state-owned listed firms is more likely to motivate employees when the gap is low, while the pay gap doesn't motivate employees when it is high. Additionally, if the pay gap results from managerial power to certain extent, it doesn't have an encouraging effect on executives.

\subsubsection{Influence Factors of Pay-Performance Sensitivity}

Many scholars have conducted in-depth research about influence factors of pay-performance sensitivity, which enriched the research about the relationship between compensation system design and the performance of enterprises.

Tafkov I. D. [13] examines the incentive effects of public or private relative performance information (RPI) on different compensation systems. The results indicate that both public RPI and private RPI have a positive effect on performance, no matter whether the compensation system is flat-wage performance-based or individual performance-based. In addition, the incentive effect of public RPI on performance is greater than that of private RPI. Though RPI has a positive effect on performance under both compensation systems, this effect is greater under an individual performance-based system. The positive effect of public RPI is greater under an individual performance-based compensation system compared with a flat-wage compensation system.

Many scholars in China also carried out research about the factors which affect pay-performance sensitivity.

$\mathrm{Lu}, \mathrm{R}$, Liu, J.H. and $\mathrm{Xu}, \mathrm{N}$. [14] investigate the relationship between internal control quality and executive pay-performance sensitivity. The results indicate that the higher internal control quality is, the higher executive pay-performance sensitivity is. Compared with non-state-owned listed firms, the relationship between internal control quality and executive pay-performance sensitivity in state-owned listed firms is more significant. In other ways, non-market pricing transactions in business groups will weaken the incentive of executive compensation, that is to say, they will have negative influences on executive payperformance sensitivity [15].

In addition, some scholars in China also studied pay-performance sensitivity based on the institutional background of China.

The credit constraints, resulting from the imperfect judicial protection on the interests of creditors, have various degrees of impact on the decisions of listed companies. Based on the particular background, Chen, J. and Xu, Y.D. [16] examine the influences of debt maturity constraints on incentive intensity of executive compensation in listed companies. The results show that the intensity of debt maturity constraints is negatively correlated with executive pay-performance sensitivity. For state-owned listed firms, the natural political relations eliminate the negative impact of debt maturity constraints, and with the weakening of the 
debt maturity constraint, the incentive intensity of executive compensation gradually increased. The results show that under the condition of strong credit constraints, companies will focus on the interests of creditors and reduce executive pay-performance sensitivity when designing the contract of executive compensation, in order to weaken executive's motivation of risk shifting. Closely integrated with China's institutional background, Tang, S. and Sun, Z. [17] examine the impact of political connections on executive's compensation in companies with the nature of different property rights, and the effect of this influence on the future performance of the companies. The results show that after controlling other economic factors and corporate governance factors which affect executive's compensation, executives of politically connected firms have received significant higher salaries, both in state-owned and non-state-owned enterprises. However, in state-owned enterprises, the excess compensation of executives caused by political connections is significantly negatively associated with the future performance of the company. However, in non-state enterprises, the excess remuneration resulted from political connection is positively correlated with the future performance of the company.

\subsection{Compensation System Design and Financial Misreporting}

As is mentioned above, the design of compensation system has an impact on performance to some extent. Specifically, compensation is an incentive factor of performance and a good compensation system design can help improve company's performance. On the other hand, the design of compensation system is also likely to prompt employees or executives to exaggerate their performance in order to obtain higher returns. That is to say, it may lead to financial misreporting.

First of all, the possibility of financial misreporting under different compensation system design is different. Maas, V.S. and Van Rinsum, M. [18] find that when a manager's performance has a positive influence on the monetary payoff of his peers, the manager is more likely to overstate his performance.

Moreover, some scholars also expand the research about the relationship between financial misreporting and equity incentive in compensation system, providing a new perspective on the study.

Some prior researches examine the relationship between financial misreporting and equity incentive and suggest that a manager whose wealth is more sensitive to the company's stock price is more likely to overstate performance. Obviously the focus of these studies is the value of company's stock. However, Armstrong, C.S., et al. [19] provides a different perspective. The risk of stocks is the volatility of stock returns. If the manager is risk-averse and financial misreporting will not only increase the value of stocks but also the risk of stocks, the manager is faced with a trade-off between risk and profit when making a decision to misreport. Unlike the conclusion of previous researches, the results of the article indicate that managers choose to exaggerate performance for the reason that their wealth is affected by the volatility of the stock returns but not the value of the stock. That is to say, in companies which implement equity incentive, it's 
not the value of the stocks but the risk of the stocks that is closely related to the financial falsification of managers.

Jayaraman, S. and Milbourn, T. [20] also point out that detection mechanisms should be taken into consideration when studying the relationship between CEO equity incentive and financial misreporting. Detection mechanisms can mitigate the impact of equity incentives on misreporting by limiting the ability of managers to carry out such manipulative activities. In the paper, auditor industry expertise is used as a kind of detection mechanism. The results show that there is a positive correlation between CEO equity incentive and financial misreporting in the sub-sample of low auditor expertise. However, there is no corresponding correlation in the sub-sample of high auditor expertise. In other words, when there is no effective detection mechanism, CEO equity incentive will have a great impact on financial misreporting. This is also an expansion of the research about the relationship between equity incentive and financial misreporting.

In addition, Singh, R. and Larkin, I. [21] examine how performance-based compensation affects managers' reporting behavior and the resulting stance auditors take when deciding whether to certify a manager's report. They document that auditor's conservatism helps improve the measurement of the performance, that is to say, the reported performance will be more real.

Some scholars in China have also conducted some research on the relationship between the design of compensation system and financial misreporting.

Deng, X.L., Chen, Y.S. and Chen, D. [22] find that the higher the degree of overlap between the Audit Committee and the Remuneration Committee, the higher the level of earnings management. What's more, in companies with high executive compensation or large internal pay gap, the correlation between the overlapping degree and earnings management is stronger, and the correlation between executive compensation and manipulative earnings is stronger, suggesting that managers may collaborate with cross-serving directors to manipulate earnings to grab higher opportunistic remuneration. The results indicate that overlapping of committees is an important factor of executive's compensation and misreporting behavior. Liu, X.M., Zhang, Y. and Wang, L. [23] document that the equity remuneration of the original top management team is positively correlated with the level of real earnings management, which indicates raising the equity compensation of the original top management team will induce real earnings management, resulting in financial misreporting.

\section{Conclusions}

Domestic and foreign scholars' study of the considerations and influences of compensation system design has expanded the research in this field, which helps people have a better understanding and application of compensation system design.

This paper has certain guiding significance to the effective application of compensation system design. This paper suggests that compensation system design 
should not only focus on the methods used to reward employees' performance, such as the combination of short-term and long-term incentives and attaching importance to the degree of team effort, but also integrate with the enterprise's conditions, for instance, corporate strategy, organizational culture, etc. In addition, enterprises should pay attention to the internal construction, such as improving internal control quality and avoiding the overlapping between the Audit Committee and the Remuneration Committee, which will help compensation system play a positive role. In the meanwhile, enterprises should make account of the application of external supervision mechanism and use auditor industry expertise to mitigate the impact of incentive measures on financial misreporting. In general, the paper can help enterprises design scientific and appropriate compensation system and contribute to the positive and effective functioning of compensation system, which has a practical significance in the development of enterprises. That is to say, it can help improve the performance of enterprises and restrain financial misreporting.

Moreover, as this paper summarizes the latest research on the considerations of compensation system design, and the influences of compensation system design on performance and financial misreporting, it provides a holistic view of the related research on compensation system design, which is helpful to explore research innovation points or new research directions in compensation system design. This is of significance to following academic research.

Generally, foreign research on compensation system design is more extensive and mature, which has some innovations. In the meanwhile, it also provides directions for the following study. For instance, it's suggested that it's not suitable for high-growth-option firms to use RPE to evaluate the performance of CEO, thus providing a new research direction: what kind of ways should be used to evaluate the performance of CEO to mitigate the risks faced by CEO?

In China, due to the existences of the nature of different property rights, different economic regions and imperfect judicial protection, which are with Chinese characteristics, the application of compensation system design should not be fully referred to foreign countries. It's necessary to integrate with China's institutional background when studying compensation system design in China. For example, in close connection with China's institutional background, it is confirmed that debt maturity constraints and political connections have an impact on executive pay-performance sensitivity [17], which has certain guiding significance. On the other hand, the research on compensation system design is not as extensive as that of foreign countries. In China, there are only a few studies on the relationship between compensation system design and financial misreporting, and related research mainly focuses on the issue of compensation incentive of executives. Consequently, it's essential for scholars in China to use the experience of other countries for reference and integrate with China's institutional background when carrying out in-depth research.

Needless to say, the research is limited by the fact that it only involves in the latest research on compensation system design and includes only compensation 
system design's considerations and influences, which are deemed to be salient. Future research could establish a clear and overall compensation system.

\section{References}

[1] Hu, Y.Q. and Zhou, H. (2012) Executive Compensation, Company's Growth and Relative Performance Evaluation-Empirical Evidence from the Sample of Listed Companies in China. Accounting Research, 5, 22-28.

[2] Albuquerque, A.M. (2013) Do Growth-Option Firms Use Less Relative Performance Evaluation? The Accounting Review, 89, 27-60.

https://doi.org/10.2308/accr-50574

[3] Drymiotes, G. and Sivaramakrishnan, K. (2012) Board Monitoring, Consulting, and Reward Structures. Contemporary Accounting Research, 29, 453-486. https://doi.org/10.1111/j.1911-3846.2011.01109.x

[4] Zhu, T. (2015) Director's Compensation, CEO's Compensation and Firm's Future Performance: Supervision or Collusion? Accounting Research, 8, 007.

[5] Díaz-Fernández, M., López-Cabrales, A. and Valle-Cabrera, R. (2013) In Search of Demanded Competencies: Designing Superior Compensation Systems. The International Journal of Human Resource Management, 24, 643-666. https://doi.org/10.1080/09585192.2012.677461

[6] Bushardt, S.C., Glascoff, D.W. and Doty, D.H. (2011) Organizational Culture, Formal Reward Structure, and Effective Strategy Implementation: A Conceptual Model. Journal of Organizational Culture, Communication and Conflict, 15, 57.

[7] Madhani, P.M. (2014) Aligning Compensation Systems with Organization Culture. Compensation \& Benefits Review, 46, 103-115.

https://doi.org/10.1177/0886368714541913

[8] Xia, N. and Dong, Y. (2014) Executive Compensation, Employee Compensation and Corporate Growth-Based on Listed SMEs in China Empirical Data. Accounting Research, 9, 012.

[9] Banker, R.D., Darrough, M.N., Huang, R., et al. (2012) The Relation between CEO Compensation and Past Performance. The Accounting Review, 88, 1-30. https://doi.org/10.2308/accr-50274

[10] Chen, C.X., Williamson, M.G. and Zhou, F.H. (2012) Reward System Design and Group Creativity: An Experimental Investigation. The Accounting Review, 87, 1885-1911. https://doi.org/10.2308/accr-50232

[11] Chen, D.H., Fan, C.L. and Shen, Y.J. (2015) Executives and Employees: Comparison and Interaction of Incentive Effectiveness. Management World, 5, 160-171.

[12] Li, W.J. and Hu, Y.M. (2012) Who Is Encouraged by Pay Dispersion in State-Owned Enterprises? Economic Research Journal, 12, 125-136.

[13] Tafkov, I.D. (2012) Private and Public Relative Performance Information under Different Compensation Contracts. The Accounting Review, 88, 327-350. https://doi.org/10.2308/accr-50292

[14] Lu, R., Liu, J.H. and Xu, N. (2011) Internal Control, Property Right and Executive Pay Performance Sensitivity. Accounting Research, 10, 42-48.

[15] Pan, H.B. and Yu, M.G. (2014) Intra-Group Transactions, Executive Compensation, and Capital Allocation Efficiency. Accounting Research, 10, 003.

[16] Chen, J. and Xu, Y.D. (2012) Are the Incentives of CEO Compensation Care for the Interest of Creditor?-Empirical Evidence from the view of Debt Maturity Constraint in China. Accounting Research, 9, 73-81. 
[17] Tang, S. and Sun, Z. (2014) The Political Connections, the CEO's Salary, and Firm's Future Management Performances. Management World, 5, 93-105.

[18] Maas, V.S. and Van Rinsum, M. (2013) How Control System Design Influences Performance Misreporting. Journal of Accounting Research, 51, 1159-1186. https://doi.org/10.1111/1475-679X.12025

[19] Armstrong, C.S., Larcker, D.F., Ormazabal, G., et al. (2013) The Relation between Equity Incentives and Misreporting: The Role of Risk-Taking Incentives. Journal of Financial Economics, 109, 327-350.

[20] Jayaraman, S. and Milbourn, T. (2015) CEO Equity Incentives and Financial Misreporting: The Role of Auditor Expertise. The Accounting Review, 90, 321-350. https://doi.org/10.2308/accr-50854

[21] Singh, R. and Larkin, I. (2015) Auditor Conservatism, Incentive Compensation, and the Quality of Financial Reporting. Journal of Law, Economics, and Organization, 31, 721-751. https://doi.org/10.1093/jleo/ewv012

[22] Deng, X.L., Chen, Y.S. and Chen, D. (2014) Committee Overlapping, Earnings Management and CEOs' Compensation. Auditing Research, 6, 13.

[23] Liu, X.M., Zhang, Y. and Wang, L. (2014) Influence of the Original TMT's Compensation Incentives on Earnings Management. Journal of Audit and Economics, 4, 61-70.

Submit or recommend next manuscript to SCIRP and we will provide best service for you:

Accepting pre-submission inquiries through Email, Facebook, LinkedIn, Twitter, etc. A wide selection of journals (inclusive of 9 subjects, more than 200 journals)

Providing 24-hour high-quality service

User-friendly online submission system

Fair and swift peer-review system

Efficient typesetting and proofreading procedure

Display of the result of downloads and visits, as well as the number of cited articles

Maximum dissemination of your research work

Submit your manuscript at: http://papersubmission.scirp.org/

Or contact me@scirp.org 